\title{
Systemic therapy for advanced hepatocellular carcinoma: targeted therapies
}

\author{
Sri Harsha Tella ${ }^{1,2}$, Anuhya Kommalapati ${ }^{2}$, Amit Mahipal ${ }^{3}$ \\ ${ }^{1}$ Department of Internal Medicine, University of South Carolina School of Medicine, Columbia, SC, USA; ${ }^{2}$ Department of Gastrointestinal \\ Oncology, H. Lee Moffitt Cancer Center, Tampa, FL, USA; ${ }^{3}$ Department of Medical Oncology, Mayo Clinic, Rochester, MN, USA \\ Contributions: (I) Conception and design: All authors; (II) Administrative support: A Mahipal; (III) Provision of study materials or patients: All \\ authors; (IV) Collection and assembly of data: All authors; (V) Data analysis and interpretation: All authors; (VI) Manuscript writing: All authors; (VII) \\ Final approval of manuscript: All authors. \\ Correspondence to: Amit Mahipal, MD, MBBS, MPH. Department of Medical Oncology, Mayo Clinic, 200 1st street SW, Rochester, MN 55906, \\ USA. Email: Mahipal.amit@mayo.edu.
}

\begin{abstract}
Therapeutic options for advanced, unresectable hepatocellular carcinoma (HCC) have changed dramatically over the last 3 years. While surgical resection, orthotropic liver transplantation, and localized therapeutic options such as ablation, radiation therapy, and embolization remain therapeutics of choice in localized disease, systemic therapy is the only option in advanced, metastatic HCC. Since the United States Food and Drug Administration (US FDA) approval of sorafenib in 2008, targeted therapies such as sunitinib, tivantinib, brivanib, erlotinib, and linifanib; monoclonal antibody- bevacizumab showed no meaningful improvement in treatment of HCC. However, with improved understanding on the molecular pathophysiology and tumor heterogeneity of HCC, we have made progress in expanding the therapeutic options in advanced HCC. Targeted therapy with lenvatinib, cabozantinib, and regorafenib; monoclonal antibody ramucirumab; immunotherapies nivolumab and pembrolizumab have demonstrated promising results in the clinical trials. The current work outlines the molecular mechanisms and tumorigenesis of HCC, a detailed discussion of the trial results of the approved therapies in HCC, future perspectives and potential options to overcome the challenges of systemic therapy in HCC.
\end{abstract}

Keywords: Liver cancer; targeted therapy; sorafenib; lenvatinib

Submitted Mar 11, 2020. Accepted for publication Apr 29, 2020.

doi: $10.21037 /$ cco-20-117

View this article at: http://dx.doi.org/10.21037/cco-20-117

\section{Introduction}

Hepatocellular carcinoma (HCC) is the most common primary liver malignancy attributing to third highest cancerrelated deaths globally (1). While majority of cases were reported in Asia-Pacific and sub-Sahara region historically, rising incidence is seen in the Western World due to higher rates of non-alcoholic fatty liver disease (NAFLD) (2). The incidence of HCC is closely related to advanced liver disease with various risk factors such as infections, toxins, and metabolic factors all leading to cirrhosis (3-5). The chronic inflammation and immunosuppressive environment in cirrhotic liver has been shown to promote
HCC tumorigenesis. Given the heterogeneity in the risk factors and molecular pathways contributing to HCC tumorigenesis, it poses a major therapeutic challenge especially at advanced stages of diagnosis.

Management of HCC is primarily based on the stage at diagnosis, underlying liver function, patient's age, and medical comorbidities (6). Surgical resection is the preferred therapy of choice for patients in localized disease without any macrovascular invasion. Alternatively, in surgically unresectable patients with solitary lesion less than $5 \mathrm{~cm}$ or three lesions each less than $3 \mathrm{~cm}$ (no macrovascular invasion; no nodal or distant metastases), liver transplantation can be potentially curative. In patients 
with liver confined disease with no macrovascular invasion who are not candidates for surgical resection or orthotropic liver transplantation, liver directed therapies are preferred approach (6). Liver directed therapies may also aid in downstaging the tumor rendering the patients potentially resectable or eligible for transplantation (7).

Unfortunately, $>50 \%$ patients with HCC are diagnosed at advanced stage rending systemic therapy as the only therapeutic option (8). In addition, approximately $70 \%$ of the patients who undergo surgical resection of the primary tumor develop recurrences (9). Systemic therapy is preferred in patients who had extensive recurrence or in those liver-directed therapies may not be an option. Currently, sorafenib and lenvatinib are United States Food and Drug Administration (US FDA) approved first-line therapies for advanced HCC. In patients who progressed or did not tolerate sorafenib, second-line options include cabozantinib, regorafenib, ramucirumab [for patients with alpha-fetoprotein (AFP) levels $>400 \mathrm{ng} / \mathrm{mL}$ ], nivolumab, and pembrolizumab. Most recently, US FDA approved the use of NTRK inhibitors larotrectinib or entrectinib in patients with NTRK fusion-positive solid malignancies, which include advanced HCC. Although cytokine therapy (interferon alpha-2b, interleukin-12) yielded not so encouraging results $(10,11)$, nivolumab and pembrolizumab have shown encouraging results in terms of PFS in phase II trials $(12,13)$. Unfortunately, phase III trials of nivolumab in first line setting and pembrolizumab in second line setting did not meet their primary end points $(14,15)$. Preliminary results of phase III trial demonstrated OS and PFS benefit with atezolizumab plus bevacizumab compared to sorafenib as first line treatment for HCC (16).

Development of effective therapies for HCC is hampered by the tumor heterogeneity stemming from multifactorial risk factors. A better understanding on the heterogenic tumorigenic pathways will hopefully shed light on tumor biomarkers, genomics and other tumor factors that predict targeted therapy response in HCC. In the present work, we sought to discuss the tumorigenesis of HCC, clinical trials that evaluated the drugs targeting these tumorigenic pathways, and outline future directions of targeted therapy in advanced HCC.

\section{HCC tumorigenesis}

Next generation whole exome and RNA sequencing have demonstrated that HCC is a complex and heterogenous tumor. Despite the presence of various risk factors, majority of HCC tumors are preceded by common tumorigenic pathway of chronic inflammation and fibrosis. Histological examination of these lesions has shown the background of cirrhosis and islands of dysplastic lesions (both low- and high-grade) (17). Interestingly, HCC exhibits significant heterogeneity both clinically and histopathologically ranging from well- to poorly differentiated lesions even with in the same liver. As in any other solid organ malignancies, gene mutations, copy number variations, gene rearrangements, and epigenetic modifications were shown to play a key role in HCC tumorigenesis. Unlike melanoma and lung cancer, HCC is known to harbor $20-100$ genetic mutations per genome (intermediate-range) (18). Most common genetic mutations implicated in HCC tumorigenesis are TERT promoter mutations (30-60\%), TP53 (18-50\%), AXIN1/2, ARID1A/2, and $\beta$-catenin gene (18-40\%) (17). The gene mutation number and the type of gene involved is primarily dependent on the underlying etiological factor. For instance, hepatitis B virus (HBV) associated HCC is known to have high number of mutations per genome given the RNA mediated replication of HBV. HCC tissue samples integrated with HBV were shown to have increased TERT promotor mutations (19). Notably, genetic aberrations in TERT has been implicated in premature liver fibrosis (20). In contrast, $\mathrm{HCV}$ causes gene mutations by causing DNA breaks especially in TP53, CTNNB, and BCL-6 genes (17). A considerable high number of TP53 mutation harboring HCC are seen in the geographical areas with high prevalence of $\mathrm{HCV}(17,21,22)$. In addition to TP53 mutations, HCV infection is known to target mitogen-activated protein kinase (RAS/MAPK) pathways and JAK/STAT contributing to tumorigenesis (21).

Molecular studies identified DNA methylation defects especially in the genes RASSF1A, SOCS-3, CDKNA2, $M G M T$, and GSTP1 as one of the potential contributors of HCC tumorigenesis (23-26). While both HBV and HCV are generally implicated in DNA methylation defects, Wntsignaling pathway is particularly targeted by HCV (27-29). $\mathrm{HCV}$ proteins NS3 and NS5 need a special mention here as they were shown to alter micro-RNA-155 expression, which potentiates tumor necrosis factor-alpha $(\mathrm{TNF}-\alpha)$ levels thereby contributing to tumorigenesis (30).

Chronic viral infection (HBV, HCV) and exposure to toxins such as aflatoxin and alcohol results in upregulation of cellular signaling pathways especially epidermal growth factor (EGF), hepatocyte growth factor (HGF/c-Met), insulin-like growth factor, and platelet-derived growth factor (PDGF). These ligands are particularly implicated 
in cell differentiation pathways (Notch, Wnt-signaling). In addition, angiogenic pathways such as vascular endothelial growth factor (VEGF) and fibroblast growth factor (FGF) mediated pathways are also upregulated by activating receptor tyrosine kinases in P13K/AKT/mTOR and Ras/ Raf/MEK/ERK (MAPK) cascades (31).

In general, hepatic tissue is exposed to higher degree of antigens from gastrointestinal tract. To survive this massive antigen exposure, augmented interleukins 4, 5, 8, and 10 aid in creating an immunosuppressive environment in hepatic tissue. This immune suppressive environment results from an inhibition of myeloid cell arginase- 1 and galectin-9 activity and increased expression of check points (programmed-cell death pathway) (32). In addition, immune-activating cytokines (interleukin 1, TNF, interferon-gamma) are suppressed (17). This intrinsic immune suppressive environment helps in creating a fertile soil for carcinogenesis and tumor progression. Further, higher percentage of myeloid-derived suppressor cells (MDSCs) and regulatory T-cells are seen in HCC (33).

Interestingly, a higher percent of intratumor heterogeneity especially in terms of histology, proliferation, genomic mutations and activated receptor tyrosine kinases (64\% and $25-47 \%$ in HCC measuring $3-5,<2 \mathrm{~cm}$ in diameter, respectively) (34). A single institution analysis of 120 HCC tumors from 23 patients showed intratumoral heterogeneity in $87 \%$ (20 of 23 patients). Among these patients, $26 \%$ had morphologic heterogeneity whereas morphologic and immunohistochemical heterogeneity was seen in 39\% (35). This inter- and intratumor heterogeneity represents a major challenge potentially attributing to drug resistance and treatment failure. This tumor heterogeneity also makes things harder to develop a predictable tissue biomarker in HCC. As detailed earlier, approximately $70 \%$ of early stage HCC recur after curative resection. It is possible that this recurrent cancerous lesion may be a metastatic lesion of the primary tumor or may be a new second primary HCC. Moreover, given the multifactorial etiology, "field cancerization" effect has been welldocumented in HCC resulting in multiple synchronous primary lesions in HCC (36). This is of particular concern in developing effective targeted therapy as we may be missing the activated downstream signaling pathway in unbiopsied lesion (37). In the subsequent sections, we discuss the various targeted therapies evaluated in phase II and III clinical trials in HCC with a special focus on challenges and future directions that potentially help in improving outcomes.

\section{Targeted therapy in advanced, inoperable HCC}

\section{Sorafenib}

Sorafenib, a multi-kinase inhibitor that primarily targets VEGFRs 1, 2, and 3, PDGFR, c-kit, STAT3 pathway (38), and cell cycle (39) was approved by the US FDA in 2008. The drug showed encouraging results in terms of median OS in advanced HCC in two landmark randomized trials $(40,41)$. In a phase III trial, patients with advanced HCC who are treatment naive were randomized to receive either sorafenib or placebo (SHARP trial). Compared to placebo, sorafenib resulted in significantly better median OS (10.7 vs. 7.9 months; $\mathrm{P}=0.001)$. Similar promising results were seen in another randomized trial in Asia-Pacific region that showed a better median OS (6.5 vs. 4.2 months, $\mathrm{P}=0.01$ ). Interestingly, on sub-group analysis, the participants in Asia-Pacific region study that harbored HCV had a better response with sorafenib. In both the trials (SHARP and Asia-Pacific trials), sorafenib benefit was much more evident in patients that had no extra-hepatic spread, HCV infection, and lower neutrophil-to-lymphocyte ratio. Both the trials demonstrated similar side effect profile of sorafenib, which included fatigue, weight loss, diarrhea, palmar-plantar skin reaction, and low phosphorous levels. Notably, none of the participants in sorafenib cohort had a complete response and $1 \%$ of the active drug cohort demonstrated overall response per as evaluated by the Response Evaluation Criteria in Solid Tumors (RECIST) criteria. Interestingly, both the trials included only the patients with good performance status of Eastern Cooperative Oncology Group (ECOG) 0 or $1(90 \%)$ and good hepatic function $(95 \%$ and $5 \%$ of patients in sorafenib group were of Child-Pugh class A and class B, respectively). An observational registry evaluated the safety of sorafenib in higher Child-Pugh scores, which showed that the drug had a tolerable safety profile in high Child-Pugh groups, too (42). However, median OS was only 5.2 months in patients with Child-Pugh B status demonstrating limited benefit (43).

Given the encouraging results seen with sorafenib monotherapy, the drug was evaluated in combination with doxorubicin in the patients with advanced HCC $(n=96)(44)$. Compared to doxorubicin monotherapy, the combination group resulted in delayed time to progression (6.4 vs. 2.8 months; $\mathrm{P}=0.02)$ and median OS (13.7 vs. 6.7 months; $\mathrm{P}=0.006$ ) (44). Unfortunately, these encouraging results were not replicated in a phase III trial (Table 1) (45). Similar disappointing results were seen in another phase III trial (SEARCH) that evaluated the combination sorafenib and 
Table 1 Selected phase III trials of the agents approved targeted therapies in advanced HCC

\begin{tabular}{|c|c|c|c|c|c|c|c|}
\hline Agent & Study (n) & Dose evaluated & Targets & $\begin{array}{l}\text { Patients with } \\
\text { portal vein } \\
\text { invasion }\end{array}$ & ORR & PFS & OS \\
\hline Sorafenib & $\begin{array}{l}\text { Asia-Pacific }(n=226) \\
(41)\end{array}$ & $\begin{array}{l}\text { Sorafenib } 400 \text { mg twice } \\
\text { daily vs. placebo }\end{array}$ & kinases, and c-kit & Included & $3.3 \%$ & 2.8 months & 6.5 months \\
\hline Lenvatinib & $\begin{array}{l}\text { Kudo et al., (n=954) } \\
\text { (46) }\end{array}$ & $\begin{array}{l}\text { Lenvatinib } 12 \mathrm{mg} \text { once } \\
\text { daily (>60 kg body } \\
\text { weight), } 8 \mathrm{mg} \text { (<60 kg } \\
\text { body weight) vs. sorafenib } \\
400 \mathrm{mg} \text { twice daily }\end{array}$ & $\begin{array}{l}\text { EGFR1-3, FGFR } \\
\text { 1-4, PDGFR, and } \\
\text { c-kit }\end{array}$ & Excluded & $\begin{array}{l}24.1 \% \\
\text { vs. } 9.2 \%\end{array}$ & $\begin{array}{l}7.4 \text { vs. } 3.7 \\
\text { months }\end{array}$ & $\begin{array}{l}13.6 \text { vs. } \\
12.3 \text { months }\end{array}$ \\
\hline Cabozantinib & $\begin{array}{l}\text { CELESTIAL trial } \\
(\mathrm{n}=707)(47)\end{array}$ & $\begin{array}{l}\text { Cabozantinib } 60 \text { mg } \\
\text { once daily vs. placebo }\end{array}$ & $\begin{array}{l}\text { AXL, MET, and } \\
\text { VEGFR2 }\end{array}$ & Included & $\begin{array}{l}4 \% \text { vs. } \\
0.4 \%\end{array}$ & 5.2 months & 10.2 months \\
\hline Regorafenib & $\begin{array}{l}\text { RESORCE trial } \\
(n=573)(48)\end{array}$ & $\begin{array}{l}\text { Regorafenib } 160 \text { mg } \\
\text { once daily vs. placebo }\end{array}$ & $\begin{array}{l}\text { VEGFR1, } 2 \text { and 3; } \\
\text { PDGFR, c-kit, and } \\
\text { FGFR }\end{array}$ & Included & $\begin{array}{l}11 \% \text { vs. } \\
4 \%\end{array}$ & 3 months & 10.6 months \\
\hline \multirow[t]{2}{*}{ Ramucirumab } & $\begin{array}{l}\text { REACH trial }(n=565) \\
(49)\end{array}$ & $\begin{array}{l}\text { Ramucirumab }(8 \mathrm{mg} / \mathrm{kg}) \\
\text { or placebo }\end{array}$ & VEGFR-2 & Included & $7 \%$ & 2.8 months & 9.2 months \\
\hline & $\begin{array}{l}\text { REACH-2 trial } \\
(n=292)(50)\end{array}$ & $\begin{array}{l}\text { Ramucirumab }(8 \mathrm{mg} / \mathrm{kg}) \\
\text { or placebo }\end{array}$ & & Included & $5 \%$ & 2.8 months & 8.5 months \\
\hline
\end{tabular}

HCC, hepatocellular carcinoma; ORR, overall response rate; PFS, progression free survival; OS, overall survival of active drug therapy cohort; VEGFR, vascular endothelial growth factor receptors; RAF, rapidly accelerated fibrosarcoma; EGFR, epidermal growth factor receptor; FGFR, fibroblast growth factor receptor; PDGFR, platelet derived growth factor receptor.

erlotinib (51). The combination did not show any benefit in terms of median OS (9.5 vs. 8.5 months, $\mathrm{P}=0.41)$ and PFS (3.2 vs. 4 months, $\mathrm{P}=0.18$ ).

Despite the encouraging results as monotherapy, sorafenib did not show OS benefit when combined with trans-arterial chemoembolization (TACE) (52-54). In addition, a phase III trial (STORM) showed no benefit of sorafenib in adjuvant setting in terms of recurrence free survival and median OS (55). Moreover, a recent metaanalysis that evaluated sorafenib as an adjuvant therapy in patients with localized HCC demonstrated no significant benefit in terms of recurrence and median OS (56).

\section{Lenvatinib}

After the US FDA approval of sorafenib in 2008, there has been a sad saga of 10 years in which no targeted therapy has shown clinically significant OS benefit in advanced HCC. After a decade, lenvatinib received approval from the US FDA as a first-line therapy in advanced, inoperable HCC given its impressive outcomes in terms of OS and PFS. Lenvatinib is a small molecule tyrosine kinase inhibitor targeting EGFR 1-3, FGFR 1-4, PDGFR, RET and c-kit. In a phase II trial involving patients with advanced, inoperable HCC $(\mathrm{n}=46)$, lenvatinib resulted in a median OS and PFS of 18.7 and 12.8 months, respectively and $47 \%$ of the patients had stable disease as best response (57). Lenvatinib was compared to sorafenib in a phase III noninferiority trial which showed a better PFS (7.4 vs. 3.7 months; $\mathrm{P}<0.0001)$ and time to progression (8.9 vs. 3.7 months; $\mathrm{P}<0.0001)$ as compared to that of sorafenib arm (46). In addition, lenvatinib was shown to be non-inferior 
to sorafenib in advanced HCC in terms of OS (13.6 vs. 12.3 months). Objective response rate was higher in lenvatinib group as compared to that of sorafenib group ( $24 \%$ vs. $9 \%$ as per modified RECIST criteria). While treatment-related adverse events were similar in both the arms, serious adverse events were higher in lenvatinib group. Proteinuria was the most common treatment related adverse event leading to treatment discontinuation. Given the non-inferiority nature of lenvatinib (as compared to sorafenib) and a tolerable safety profile-the drug is approved for the use in advanced, inoperable HCC by various regulatory medical agencies across the World.

Although lenvatinib resulted in non-inferiority results as compared to sorafenib, a number of questions are yet to be answered. For instance, there is a lack of specific data or biomarkers that would help the practicing physicians choose between lenvatinib vs. sorafenib. Moreover, recently, US FDA approved regorafenib, cabozantinib, ramucirumab (in AFP >400 $\mathrm{ng} / \mathrm{mL}$ ), nivolumab, pembrolizumab in the patients who progressed on sorafenib. It is yet to be determined if these agents would be beneficial in the patients who used lenvatinib as first-line therapy as lenvatinib targets FGFR, KIT, and RET pathways, which was not the case with sorafenib (58). Moreover, patients with invasion of main portal vein and bile ducts and $>50 \%$ involvement of liver were excluded from the clinical trial. It is yet to be determined how the drug is tolerated by all advanced HCC patients across the World. Lenvatinib is also currently being evaluated in combination with pembrolizumab in a phase III trial in patients with advanced HCC (59).

\section{Cabozantinib}

Cabozantinib, a tyrosine kinase inhibitor acts by targeting AXL, MET, and VEGFR2 proteins. The drug has shown promising results in advanced HCC patients who progressed on first-line sorafenib therapy $(47,60)$. In a phase II trial $(\mathrm{n}=41)$, the drug resulted in median PFS and OS of 5.2 and 11.5 months, respectively, with a tumor regression rate and objective response rate of $78 \%$ and $5 \%$, respectively. The drug was tolerated well with most common grade $\geq 3$ adverse events being diarrhea (20\%), palmar-plantar syndrome (15\%), and low platelet count $(15 \%)(60)$. Given the promising results, the drug was further evaluated in a phase III trial (CELESTIAL trial) (47) $(\mathrm{n}=707)$ in advanced HCC patients who progressed on sorafenib. The trial allowed receipt of up to two prior systemic therapy. The drug showed encouraging results in reducing the risk of death by $24 \%$ as compared to that of placebo. The drug resulted in statistically and clinically meaningful benefit in terms of PFS (5.2 vs. 1.9 months; $\mathrm{P}<0.0001$ and median OS (10.2 vs. 8 months, $\mathrm{P}=0.004)$. Cabozantinib group had higher percentage of grade $\geq 3$ adverse events including hand-foot syndrome (17\%), high blood pressure (16\%), and elevated liver enzyme- aspartate aminotransferase (12\%), loose stools (10\%), and fatigue $(10 \%)$. Given the encouraging results in terms of PFS and OS and tolerable safety profile, the drug was approved by the US FDA for the use in advanced HCC that progressed on first-line sorafenib therapy.

Recently, results of cabozantinib in combination with immunotherapy (nivolumab and ipilimumab) were presented in annual gastrointestinal oncology symposium, 2020 (61). Cabozantinib was evaluated as a doublet therapy (in combination with nivolumab, $\mathrm{n}=36$ ) or as a triple therapy (in combination with nivolumab and ipilimumab, $\mathrm{n}=35$ ). The double therapy and triple therapy resulted in overall response rate of $17 \%$ and $26 \%$, respectively. The triple therapy had higher rates of grade $>3$ adverse events as compared to the combination of cabozantinib and nivolumab ( $42 \%$ vs. $71 \%$ ). Cabozantinib is currently being evaluated in combination with atezolizumab as a first-line therapy in advanced, inoperable HCC (NCT03755791). These combination therapies will hopefully provide valuable therapeutic options in advanced HCC.

\section{Regorafenib}

Regorafenib is a multi-tyrosine kinase inhibitor that targets VEGFR 1, 2, and 3, PDGFR, FGFR, RAF, RET, and c-kit. The drug was evaluated in a phase II trial in patients with advanced HCC that progressed on sorafenib therapy $(n=36)$ with Barcelona Clinic Liver Cancer Stage B or C HCC and Child-Pugh class A (62). In this phase II trial, regorafenib resulted in median time to progression and OS of 4.3 and 13.8 months, respectively. Most common adverse events noted were hand-foot syndrome (53\%), diarrhea (53\%), fatigue $(53 \%)$, decreased thyroid function $(42 \%)$ and high blood pressure $(36 \%)$. In a phase III trial that randomized advanced, inoperable HCC patients that progressed on sorafenib $(n=573)$ into best supportive care plus either regorafenib $160 \mathrm{mg}$ once daily (a cycle of 3 weeks on/1 week off) arm or placebo $(n=194)$ arm (48). Regorafenib resulted in promising results in terms of median time to progression ( 3 vs. 1.5 months; $\mathrm{P}<0.001$ ), 
PFS ( 3 vs. 1.5 months; $\mathrm{P}<0.001)$ and median OS (10.6 vs. 7.8 months; $\mathrm{P}<0.0001)(48)$.

\section{Ramucirumab}

Ramucirumab is a human IgG1 monoclonal antibody blocking VEGFR-2 that has been approved by the US FDA for the use in advanced HCC that progressed on sorafenib. In a phase II trial $(\mathrm{n}=42)$, ramucirumab yielded a median OS of 12 months (63). While the drug was tolerated well, the most common grade $\geq 3$ adverse events were high blood pressure, gastrointestinal bleeding, infusion-related reaction, and fatigue. In a phase III trial (REACH) involving advanced HCC who progressed or did not tolerate sorafenib $(n=563)$, ramucirumab resulted in a non-significant benefit in median OS (9.2 vs. 7.6 months, compared to placebo, $\mathrm{P}=0.14$ ) (49). However, on sub-group analysis in patients with Child-Pugh A class and AFP level $>400 \mathrm{ng} / \mathrm{mL}$ (or $>1.5$ times the upper limit), ramucirumab showed OS advantage as compared to that of placebo (HR: 0.67; $\mathrm{P}=0.01$ ). REACH-2 phase III trial evaluated ramucirumab in advanced HCC patients with elevated AFP levels (>400 ng/mL) (50). Ramucirumab arm had a significantly better median OS ( 8.5 vs. 7 months; $\mathrm{P}=0.01$ ) and PFS ( 3 vs. 1.6 months, $\mathrm{P}<0.01$ ) as compared to that of placebo. Given the promising results in this particular subgroup of AFP $>400 \mathrm{ng} / \mathrm{mL}$, the drug is approved by the US FDA for the use in this subset of advanced HCC who progressed on sorafenib therapy.

Table 1 summarizes the phase III clinical trials of currently approved targeted therapies in advanced HCC.

\section{Current management}

Lenvatinib and sorafenib are FDA approved for firstline treatment of HCC. Lenvatinib does have higher PFS and response rates. In patients where response may be required such as impending liver failure, lenvatinib may be preferred over sorafenib. However, the cost of the drug also needs to be considered. Preliminary results suggest that combination of atezolizumab plus bevacizumab has better survival compared to sorafenib. Thus, atezolizumab plus bevacizumab will likely become standard first line treatment for HCC. However, patients who have untreated varices, high risk of bleeding, severe autoimmune disease or other contraindications to immunotherapy may benefit from treatment with tyrosine kinase inhibitors. Multiple agents are approved for patients who have progressed on sorafenib including cabozantinib, regorafenib, and ramucirumab. Unfortunately, there is no good biomarker to determine optimal treatment strategy. Though lenvatinib is approved as a first-line agent in advanced HCC, no data exists on the second-line therapies that progressed on lenvatinib. Encouragingly, multiple trials are also evaluating combination of immunotherapy and tyrosine kinase inhibitors.

\section{Future directions}

The incidence of HCC tripled since 1980 and is forecasted to rise until 2030 in all patient cohorts except Asians (64). Thanks to next generation sequencing and other molecular studies that improved our understanding on the carcinogenesis of HCC. Despite this improved understanding on the tumorigenesis, advanced HCC continues to represent a major challenge due to its tumor heterogeneity that was evident on DNA ploidy analysis and DNA fingerprinting (36). This tumor heterogeneity is of a major challenge to develop an effective targeted therapy. It is clinically not feasible to biopsy all the lesions in multicentric tumors. One potential option is evaluating the role of circulating tumor cells (CTCs) and ctDNA, which may help in identifying more tumor types or heterogeneity as the therapy proceeds. However, we need more data to standardize the CTCs and ctDNA in HCC.

One potential option is evaluating the combination of combination therapies that may target the tumorigenesis at multiple levels. The role of hypoxia-inducible factor $1 \alpha$ (HIF-1 $\alpha$ ) in HCC tumorigenesis has been well- established, especially in the tumors that have rapid growth. Such tumors with high level of HIF-1 $\alpha$ expression were shown to have poor prognosis. Preclinical studies have shown that tumor hypoxia considerably increase the PD-L1 expression on tumor and immune cells especially on MDSCs, dendritic cells, and monocytes. Hence, one of the potential areas for exploration would be evaluating the combination of immune check point inhibitors and check point inhibitors, which help in targeting the two primary mechanisms of HCC tumorigenesis. The other potential barrier is lack of predictive biomarkers, which help the clinicians in picking the right drug of choice in the right clinical scenario. For instance, ramucirumab may be an option especially in the patients with AFP levels $>400 \mathrm{ng} / \mathrm{mL}$ but no such clearcut criteria are available for other agents. Developing such criteria and biomarkers would help clinicians to choose therapy in appropriate clinical context. 
In conclusion, improved understanding of HCC tumorigenesis, developing standard biomarkers, evaluating the role of CTCs and finally evaluating the combination of various treatment modalities may potentially help us in targeting this dismal tumor, especially in advanced stages.

\section{Acknowledgments}

Funding: None.

\section{Footnote}

Provenance and Peer Review: This article was commissioned by the Guest Editors (Mehmet Akce and Shishir K. Maithel) for the series "Hepatocellular Carcinoma" published in Chinese Clinical Oncology. The article was sent for external peer review organized by the Guest Editors and the editorial office.

Conflicts of Interest: All authors have completed the ICMJE uniform disclosure form (available at http://dx.doi. org/10.21037/cco-20-117). The series "Hepatocellular Carcinoma" was commissioned by the editorial office without any funding or sponsorship. AM reports other from Eisai, other from Merck, outside the submitted work. The other authors have no other conflicts of interest to declare.

Ethical Statement: The authors are accountable for all aspects of the work in ensuring that questions related to the accuracy or integrity of any part of the work are appropriately investigated and resolved.

Open Access Statement: This is an Open Access article distributed in accordance with the Creative Commons Attribution-NonCommercial-NoDerivs 4.0 International License (CC BY-NC-ND 4.0), which permits the noncommercial replication and distribution of the article with the strict proviso that no changes or edits are made and the original work is properly cited (including links to both the formal publication through the relevant DOI and the license). See: https://creativecommons.org/licenses/by-nc-nd/4.0/.

\section{References}

1. Global Burden of Disease Liver Cancer Collaboration, Akinyemiju T, Abera S, et al. The burden of primary liver cancer and underlying etiologies from 1990 to 2015 at the global, regional, and national level: results from the global burden of disease study 2015. JAMA Oncol 2017;3:1683-91.

2. Singal AG, Lampertico P, Nahon P. Epidemiology and surveillance for hepatocellular carcinoma: New trends. J Hepatol 2020;72:250-61.

3. Jemal A, Bray F, Center MM, et al. Global cancer statistics. CA Cancer J Clin 2011;61:69-90.

4. Makarova-Rusher OV, Altekruse SF, McNeel TS, et al. Population attributable fractions of risk factors for hepatocellular carcinoma in the United States. Cancer 2016;122:1757-65.

5. Masuoka HC, Chalasani N. Nonalcoholic fatty liver disease: an emerging threat to obese and diabetic individuals. Ann N Y Acad Sci 2013;1281:106-22.

6. Forner A, Reig M, Bruix J. Hepatocellular carcinoma. Lancet 2018;391:1301-4.

7. Yao FY, Kerlan RK Jr, Hirose R, et al. Excellent outcome following down-staging of hepatocellular carcinoma prior to liver transplantation: an intention-to-treat analysis. Hepatology 2008;48:819-27.

8. Yang JD, Hainaut P, Gores GJ, et al. A global view of hepatocellular carcinoma: trends, risk, prevention and management. Nat Rev Gastroenterol Hepatol 2019;16:589-604.

9. Tabrizian P, Jibara G, Shrager B, et al. Recurrence of hepatocellular cancer after resection: patterns, treatments, and prognosis. Ann Surg 2015;261:947-55.

10. Llovet JM, Sala M, Castells L, et al. Randomized controlled trial of interferon treatment for advanced hepatocellular carcinoma. Hepatology 2000;31:54-8.

11. Sangro B, Mazzolini G, Ruiz J, et al. Phase I trial of intratumoral injection of an adenovirus encoding interleukin-12 for advanced digestive tumors. J Clin Oncol 2004;22:1389-97.

12. El-Khoueiry AB, Melero I, Crocenzi TS, et al. Phase I/II safety and antitumor activity of nivolumab in patients with advanced hepatocellular carcinoma (HCC): CA209-040. J Clin Oncol 2015;33:LBA101.

13. Zhu AX, Finn RS, Edeline J, et al. Pembrolizumab in patients with advanced hepatocellular carcinoma previously treated with sorafenib (KEYNOTE-224): a non-randomised, open-label phase 2 trial. Lancet Oncol 2018;19:940-52.

14. Yau T, Park JW, Finn RS et al. Checkmate 459: A randomized, multi-center phase 3 study of nivolumab (NIVO) vs sorafenib (SOR) as first-line (1L) treatment in patients (pts) with advanced hepatocellular carcinoma (AHCC). Ann Oncol 2019;30:v851-934. 
15. Finn RS, Ryoo BY, Merle P, et al. Pembrolizumab as second-line therapy in patients with advanced hepatocellular carcinoma in KEYNOTE-240: a randomized, double-blind, phase III trial. J Clin Oncol 2020;38:193-202.

16. Cheng AL, Qin S, Ikeda M et al. IMbrave150: Efficacy and safety results from a ph III study evaluating atezolizumab (atezo) + bevacizumab (bev) vs sorafenib (Sor) as first treatment (tx) for patients (pts) with unresectable hepatocellular carcinoma (HCC). Ann Oncol 2019;30:ix186-7.

17. Dhanasekaran R, Bandoh S, Roberts LR. Molecular pathogenesis of hepatocellular carcinoma and impact of therapeutic advances. F1000Res 2016. doi: 10.12688/ f1000research.6946.1.

18. Li S, Mao M. Next generation sequencing reveals genetic landscape of hepatocellular carcinomas. Cancer Lett 2013;340:247-53.

19. Sung WK, Zheng H, Li S, et al. Genome-wide survey of recurrent HBV integration in hepatocellular carcinoma. Nat Genet 2012;44:765-9.

20. Totoki Y, Tatsuno K, Covington KR, et al. Transancestry mutational landscape of hepatocellular carcinoma genomes. Nat Genet 2014;46:1267-73.

21. Cleary SP, Jeck WR, Zhao X, et al. Identification of driver genes in hepatocellular carcinoma by exome sequencing. Hepatology 2013;58:1693-702.

22. Kan Z, Zheng H, Liu X, et al. Whole-genome sequencing identifies recurrent mutations in hepatocellular carcinoma. Genome Res 2013;23:1422-33.

23. Zhang YJ, Ahsan H, Chen Y, et al. High frequency of promoter hypermethylation of RASSF1A and p16 and its relationship to aflatoxin B1-DNA adduct levels in human hepatocellular carcinoma. Mol Carcinog 2002;35:85-92.

24. Zhong S, Tang MW, Yeo W, et al. Silencing of GSTP1 gene by $\mathrm{CpG}$ island DNA hypermethylation in HBVassociated hepatocellular carcinomas. Clin Cancer Res 2002;8:1087-92.

25. Niwa Y, Kanda H, Shikauchi Y, et al. Methylation silencing of SOCS-3 promotes cell growth and migration by enhancing JAK/STAT and FAK signalings in human hepatocellular carcinoma. Oncogene 2005;24:6406-17.

26. Zhang YJ, Chen Y, Ahsan H, et al. Inactivation of the DNA repair gene O6-methylguanine-DNA methyltransferase by promoter hypermethylation and its relationship to aflatoxin B1-DNA adducts and p53 mutation in hepatocellular carcinoma. Int J Cancer 2003;103:440-4.
27. Deng YB, Nagae G, Midorikawa Y, et al. Identification of genes preferentially methylated in hepatitis $\mathrm{C}$ virus-related hepatocellular carcinoma. Cancer Sci 2010;101:1501-10.

28. Lim JS, Park SH, Jang KL. Hepatitis C virus Core protein overcomes stress-induced premature senescence by downregulating p16 expression via DNA methylation. Cancer Lett 2012;321:154-61.

29. Park IY, Sohn BH, Yu E, et al. Aberrant epigenetic modifications in hepatocarcinogenesis induced by hepatitis B virus X protein. Gastroenterology 2007;132:1476-94.

30. McGivern DR, Lemon SM. Virus-specific mechanisms of carcinogenesis in hepatitis $\mathrm{C}$ virus associated liver cancer. Oncogene 2011;30:1969-83.

31. Kaposi-Novak P, Lee JS, Gòmez-Quiroz L, et al. Metregulated expression signature defines a subset of human hepatocellular carcinomas with poor prognosis and aggressive phenotype. J Clin Invest 2006;116:1582-95.

32. Prieto J, Melero I, Sangro B. Immunological landscape and immunotherapy of hepatocellular carcinoma. Nat Rev Gastroenterol Hepatol 2015;12:681-700.

33. Zhao HQ, Li WM, Lu ZQ, et al. Roles of Tregs in development of hepatocellular carcinoma: a meta-analysis. World J Gastroenterol 2014;20:7971-8.

34. Kenmochi K, Sugihara S, Kojiro M. Relationship of histologic grade of hepatocellular carcinoma (HCC) to tumor size, and demonstration of tumor cells of multiple different grades in single small HCC. Liver 1987;7:18-26.

35. Friemel J, Rechsteiner M, Frick L, et al. Intratumor heterogeneity in hepatocellular carcinoma. Clin Cancer Res 2015;21:1951-61.

36. Lu LC, Hsu CH, Hsu C, et al. Tumor heterogeneity in hepatocellular carcinoma: facing the challenges. Liver Cancer 2016;5:128-38.

37. Gerlinger M, Rowan AJ, Horswell S, et al. Intratumor heterogeneity and branched evolution revealed by multiregion sequencing. N Engl J Med 2012;366:883-92.

38. Tai WT, Cheng AL, Shiau CW, et al. Signal transducer and activator of transcription 3 is a major kinaseindependent target of sorafenib in hepatocellular carcinoma. J Hepatol 2011;55:1041-8.

39. Wei JC, Meng FD, Qu K, et al. Sorafenib inhibits proliferation and invasion of human hepatocellular carcinoma cells via up-regulation of p53 and suppressing FoxM1. Acta Pharmacol Sin 2015;36:241-51.

40. Llovet JM, Ricci S, Mazzaferro V, et al. Sorafenib in advanced hepatocellular carcinoma. N Engl J Med 2008;359:378-90.

41. Cheng AL, Kang YK, Chen Z, et al. Efficacy and 
safety of sorafenib in patients in the Asia-Pacific region with advanced hepatocellular carcinoma: a phase III randomised, double-blind, placebo-controlled trial. Lancet Oncol 2009; 10:25-34.

42. Lencioni R, Kudo M, Ye SL, et al. GIDEON (Global Investigation of therapeutic DEcisions in hepatocellular carcinoma and Of its treatment with sorafeNib): second interim analysis. Int J Clin Pract 2014;68:609-17.

43. Marrero JA, Kudo M, Venook AP, et al. Observational registry of sorafenib use in clinical practice across Child-Pugh subgroups: the GIDEON study. J Hepatol 2016;65:1140-7.

44. Abou-Alfa GK, Johnson P, Knox JJ, et al. Doxorubicin plus sorafenib vs doxorubicin alone in patients with advanced hepatocellular carcinoma: a randomized trial. JAMA 2010;304:2154-60.

45. Abou-Alfa GK, Shi Q, Knox JJ, et al. Assessment of treatment with sorafenib plus doxorubicin vs sorafenib alone in patients with advanced hepatocellular carcinoma: phase 3 CALGB 80802 randomized clinical trial. JAMA Oncol 2019;5:1582-8.

46. Kudo M, Finn RS, Qin S, et al. Lenvatinib versus sorafenib in first-line treatment of patients with unresectable hepatocellular carcinoma: a randomised phase 3 noninferiority trial. Lancet 2018;391:1163-73.

47. Abou-Alfa GK, Meyer T, Cheng AL, et al. Cabozantinib (C) versus placebo $(\mathrm{P})$ in patients (pts) with advanced hepatocellular carcinoma (HCC) who have received prior sorafenib: results from the randomized phase III CELESTIAL trial. J Clin Oncol 2018;36:207.

48. Bruix J, Qin S, Merle P, et al. Regorafenib for patients with hepatocellular carcinoma who progressed on sorafenib treatment (RESORCE): a randomised, double-blind, placebo-controlled, phase 3 trial. Lancet 2017;389:56-66.

49. Zhu AX, Park JO, Ryoo BY, et al. Ramucirumab versus placebo as second-line treatment in patients with advanced hepatocellular carcinoma following first-line therapy with sorafenib (REACH): a randomised, double-blind, multicentre, phase 3 trial. Lancet Oncol 2015;16:859-70.

50. Zhu AX, Kang YK, Yen CJ, et al. Ramucirumab after sorafenib in patients with advanced hepatocellular carcinoma and increased $\alpha$-fetoprotein concentrations (REACH-2): a randomised, double-blind, placebocontrolled, phase 3 trial. Lancet Oncol 2019;20:282-96.

51. Zhu AX, Rosmorduc O, Evans TR, et al. SEARCH: a phase III, randomized, double-blind, placebo-controlled trial of sorafenib plus erlotinib in patients with advanced hepatocellular carcinoma. J Clin Oncol 2015;33:559-66.
52. Chao Y, Chung YH, Han G, et al. The combination of transcatheter arterial chemoembolization and sorafenib is well tolerated and effective in Asian patients with hepatocellular carcinoma: final results of the START trial. Int J Cancer 2015;136:1458-67.

53. Kudo M, Ueshima K, Ikeda M, et al. Randomised, multicentre prospective trial of transarterial chemoembolisation (TACE) plus sorafenib as compared with TACE alone in patients with hepatocellular carcinoma: TACTICS trial. Gut 2020;69:1492-501.

54. Meyer T, Fox R, Ma YT, et al. Sorafenib in combination with transarterial chemoembolisation in patients with unresectable hepatocellular carcinoma (TACE 2): a randomised placebo-controlled, double-blind, phase 3 trial. Lancet Gastroenterol Hepatol 2017;2:565-75.

55. Bruix J, Takayama T, Mazzaferro V, et al. Adjuvant sorafenib for hepatocellular carcinoma after resection or ablation (STORM): a phase 3, randomised, double-blind, placebo-controlled trial. Lancet Oncol 2015;16:1344-54.

56. Shang J, Xu S, Zhang J, et al. Efficacy of sorafenib in patients with hepatocellular carcinoma after resection: a meta-analysis. Oncotarget 2017;8:109723-31.

57. Ikeda K, Kudo M, Kawazoe S, et al. Phase 2 study of lenvatinib in patients with advanced hepatocellular carcinoma. J Gastroenterol 2017;52:512-9.

58. Yamamoto Y, Matsui J, Matsushima T, et al. Lenvatinib, an angiogenesis inhibitor targeting VEGFR/FGFR, shows broad antitumor activity in human tumor xenograft models associated with microvessel density and pericyte coverage. Vasc Cell 2014;6:18.

59. Llovet JM, Kudo M, Cheng AL et al. Lenvatinib (len) plus pembrolizumab (pembro) for the first-line treatment of patients (pts) with advanced hepatocellular carcinoma (HCC): phase 3 LEAP-002 study. J Clin Oncol 2019;37:TPS4152.

60. Kelley RK, Verslype C, Cohn AL, et al. Cabozantinib in hepatocellular carcinoma: results of a phase 2 placebocontrolled randomized discontinuation study. Ann Oncol 2017;28:528-34.

61. Yau T, Zagonel V, Santoro A et al. Nivolumab (NIVO) + ipilimumab (IPI) + cabozantinib (CABO) combination therapy in patients (pts) with advanced hepatocellular carcinoma (aHCC): results from CheckMate 040. J Clin Oncol 2020;38:478.

62. Bruix J, Tak WY, Gasbarrini A, et al. Regorafenib as second-line therapy for intermediate or advanced hepatocellular carcinoma: multicentre, open-label, phase II safety study. Eur J Cancer 2013;49:3412-9. 
63. Zhu AX, Finn RS, Mulcahy M, et al. A phase II and biomarker study of ramucirumab, a human monoclonal antibody targeting the VEGF receptor-2, as first-line monotherapy in patients with advanced hepatocellular cancer. Clin Cancer Res 2013;19:6614-23.

Cite this article as: Tella SH, Kommalapati A, Mahipal A. Systemic therapy for advanced hepatocellular carcinoma: targeted therapies. Chin Clin Oncol 2021;10(1):10. doi: 10.21037/cco-20-117
64. Petrick JL, Kelly SP, Altekruse SF, et al. Future of Hepatocellular Carcinoma Incidence in the United States Forecast Through 2030. J Clin Oncol 2016;34:1787-94. 